\title{
aniki
}

Revista Portuguesa da Imagem em Movimento

Portuguese Journal of the Moving Image

\section{A Web e o documentário: uma dupla inseparável?} Manuela Penafria ${ }^{1}$

Compreender e interpelar o webdocumentário são os objetivos das observações a seguir apresentadas. E, desde já, avanço com uma possível resposta à pergunta do título. Se a Web (Internet) e o documentário não são uma dupla inseparável, pelo menos, aparentam ser.

\section{Para uma definiçãa}

Etimologicamente, webdocumentário é um neologismo que associa um meio, a Internet, a um género, o documentário (Gantier 2011).

A Internet contempla dimensões documentais bastante variadas. O YouTube encontra-se repleto de filmes de família, de um grande número de registos de acontecimentos quotidianos e de manifestações diversas de carácter documental, como depoimentos (sejam eles verdadeiros ou falsos). O Facebook é, em certa medida, uma variante ou reactualização do documentário biográfico. De um modo geral, as redes sociais colocam a tónica no testemunho de quem as utiliza e dão "voz" a quem, de outro modo, não teria oportunidade de se manifestar perante comunidades de maior ou menor dimensão. Mesmo a constituição de grupos restritos que contrariam a comunicação global prometida (e talvez nunca desejada), apresenta a vantagem de um utilizador encontrar eco dos seus conhecimentos, preocupações, angústias ou alegrias, ou seja, colocar-se em relação direta com o Outro.

Um outro neologismo que surge associado ao documentário em suportes digitais interativos é o de iDoc (Interactive Documentary) que aparenta ser mais abrangente que webdocumentário pois destaca a interatividade e esta pode ser exercida em diferentes suportes que não apenas a Internet. O webdocumentário será então uma forma de iDoc, uma vez que o primeiro destaca o suporte onde ocorre a interatividade (a Internet) e o segundo coloca a interatividade como o aspeto central a ter em conta, algo que não está apenas presente na Internet.

De qualquer modo, as manifestações documentais mencionadas e que parecem indicar uma relação quase inseparável entre a Internet e o documentário têm vindo a apresentar-se de modo mais

\footnotetext{
${ }^{1}$ Universidade da Beira Interior (Covilhã, Portugal).
} 
premente num largo conjunto de sites que se autointitulam de webdocumentário.

Para a Internet, o documentário não é descartado, nem se apresenta descartável já que se constitui como um património de referência e tanto o meio como o neologismo vêm, definitivamente, afirmar que o termo documentário não possui um significado estável e delimitado. Precisamente por ser difuso pode facilmente ser adotado por novas obras que pretendam realçar uma forte ligação ao munmundo da vida. O documentário não se define, experimenta-se; e a Internet tem vindo a ser o palco dessa experimentação.

Mas, uma questão a colocar é a facilidade com que o documentário se associa às tecnologias digitais interativas que têm no computador o seu principal suporte. Parece-me que tal se deve a dois fatores: por um lado, o documentário apresenta-se como uma garantia do mundo da vida se constituir senão como referente, pelo menos, como ponto de referência dos elementos multimédia e interativos; por outro lado, a construção narrativa do documentário em suportes lineares sempre foi tendencialmente fragmentada, opondose a um desenvolvimento diegético (ou seja, à construção de um tempo e espaço próprios de uma narrativa que se associa à ficção). Fragmentada no sentido em que a ligação de um plano ou cena, com o plano ou cena seguinte não depende necessariamente, nem se encontra submetida a qualquer tipo de raccord, mas é uma ligação proposta pelo realizador tal como acontece com os links a que temos acesso a partir de um determinado texto ou imagem.

Um webdocumentário não é um filme, uma vez que o termo "filme" diz respeito a uma sucessão linear de imagens e sons; o "filme" é apenas um dos vários elementos que pode fazer parte de um webdocumentário. Assim, são concebidos para serem disponibilizados e consultados individualmente por cada utilizador, na Internet. E, por definição, o webdocumentário é uma obra que opera e apresenta um recorte poético do mundo da vida, sendo composta por uma interface interativa que integra e relaciona elementos multimédia (como texto, imagem, som) e, eventualmente, elementos de comunicação (como fóruns ou chats). Por interface entende-se uma ligação, ou seja, o que nos permite aceder a um determinado conjunto de informação.

Mas, não é apenas o webdocumentário que surge como uma novidade no âmbito de uma história do documentário ao torná-lo interativo. Para a atual tecnologia, o documentário é um aliado para exercitar as suas potencialidades. O webdocumentário constitui-se como um modo de apurar e afinar os novos suportes, uma vez que, aliados ao documentário, têm oportunidade de se destacarem na sua originalidade desenvolvendo as suas capacidades de produção de obras criativas assentes na interatividade e em inovações ou renovações estéticas. Os webdocumentários poderão, pois, ser mais 
entendidos como uma evolução das tecnologias digitais interativas que como uma evolução do documentário em si. O webdocumentário favorece um entendimento das tecnologias digitais como mais que um suporte fiável de uma grande quantidade de dados.

\section{Paradigma}

A partir da história e teoria do cinema, sabemos que a corrente realista não foi inaugurada pelos filmes Lumière. Esses filmes são já, em simultâneo, realistas (ou documentais) e ficcionais, pois uma imagem, qualquer que ela seja, é sempre um duplo, uma sombra (cf. Morin 1997). Mas, o confronto, busca e criação do real, assume, no documentário, um papel de relevo e sobre o qual tem recaído a questão da representação da realidade.

Mas, a representação não é já um conceito que dê conta do atual paradigma da produção e receção das imagens. O novo paradigma assenta num relacionamento com um objeto exterior onde somos chamados não apenas a contemplar, mas a interagir. E, evitando lançar um conceito que defina e caracterize o novo paradigma de produção e receção de imagens, avanço com uma proposta para o webdocumentário: uma alteração do conceito de representação para ligação com o mundo da vida (fazendo assim uma associação entre a definição de interface e as consequências da mesma).

Se perguntar de que modo o webdocumentário vem contribuir para a compreensão do documentário, poderia então dizer que contribui no sentido de voltarmos a ver os documentários em suporte linear como uma ligação com o mundo da vida. E essa ligação pareceme ser, sobretudo, uma ligação emocional. Por emoção, adoto a conceção de Carroll (1999) para quem a emoção são afetos que incluem elementos cognitivos.

Emoções como o desejo de conhecimento, a curiosidade, a expectativa ou mesmo binómios de emoções, como a curiosidadeconfiança (confiança no documentário uma vez que se encontra - e muitas vezes se assume - comprometido com a transmissão de informações corretas) contribuem para clarificar a relação que quer o documentário em suporte linear quer o webdocumentário estimulam com a obra em si e com o conteúdo do filme ou do webdocumentário. Perante documentários que mais levantam questões éticas seria importante verificar se essas questões não estarão profundamente imbricadas nos efeitos emocionais provocados por esses mesmos documentários.

Em “O mito do cinema total”, André Bazin (1946) propõe-se compreender o cinema afirmando que o seu surgimento se deveu a um mito que dirigiu os seus inventores no caminho de uma busca obsessiva por uma arte de um "realismo integral", ou seja, que duplicasse integralmente a realidade. A influência hegemónica da 
tecnologia em si é colocada de lado a favor das ideias que fazem avançar as invenções e o seu uso. A duplicação não nos parece algo que se tenha desvanecido do horizonte dos inventores e mesmo dos utilizadores atuais, muito pelo contrário.

O webdocumentário pode fazer-nos repensar as novas tecnologias digitais interativas (já que é, também, a evolução dessas mesmas tecnologias que está em causa) mas, antes de repensar, permite confirmar as suposições de que a tecnologia tem como horizonte o hiper-realismo, aquilo que possa ser ainda mais real que a realidade (e é cada vez mais através e pela Internet que pensamos, sentimos e agimos no mundo da vida); desde os jogos de computador que imitam e constroem ambientes reais até aos webdocumentários que nos colocam em relação direta com situações e experiências de vida, o paradigma parece caminhar para um inquietante hiperrealismo.

E este paradigma teve, como primeiro momento, o HCI ("human-computer interaction"), uma expressão que remete para um utilizador que interage com o computador quando o mesmo era entendido como uma ferramenta de trabalho (Carroll 2013). Se, no caso do documentário, a questão de uma interação com um Outro é um fator de extrema relevância; e se, no suporte linear, o documentário se apresenta como o resultado da interação entre realizador e o Outro, no webdocumentário é ao utilizador que é dada (em alguns ou, eventualmente, em cada vez mais casos) essa possibilidade de interação. Assim, em vez de HCI (que reduz a relação apenas com o computador a uma interação com informação a que acedemos com uma maior ou menor facilidade) proponho a expressão HCHI "human-computer-human interaction" pois aparenta ser a ideal para enfatizar precisamente essa característica que vem do documentário e que se prolonga no webdocumentário, a de nos colocar em relação com o Outro, de interagir, participar, interferir com o Outro. Por exemplo, obras de grande sucesso na Internet são as que implicam a participação dos utilizadores (o caso mais evidente são os filmes colaborativos).

$\mathrm{Na}$ sua aceção tradicional, o conceito de meio enfatiza as qualidades físicas e a capacidade de representação desse mesmo meio e o espectador é encorajado a pensar nas intenções do autor, no conteúdo e na forma da obra, e não no utilizador ("user"). Por seu lado, os novos meios (digitais interativos) colocam a ênfase no utilizador, nas suas capacidades e comportamentos (Manovich 2001b, 7). A essas capacidades e comportamentos acrescenta-se a permanente, constante e inevitável ligação com o mundo da vida, precisamente através e com essa possibilidade de ligação constante com o Outro. No webdocumentário, o mundo da vida apresenta-se como um recorte onde as ações do utilizador assentam em muito na partilha; e este termo exemplifica o modo como os suportes digitais interativos se interligam com o mundo da vida. O webdocumentário oferece uma 
moldura e o utilizador constrói o seu próprio percurso de interação e exploração, com a possibilidade sempre iminente de um diálogo constante e contínuo assente, sobretudo, na partilha de experiências de vida.

O interesse do webdocumentário passa mais por um pensar e interagir com e sobre o mundo da vida que por uma sua representação. Por consequência, a validade do conhecimento torna-se circunstancial, deixa de haver significados estáveis e totalizantes (como, em grande parte, eram propostos pelo documentário em suporte linear) havendo agora uma constante modelação por contingências diversas, essencialmente a partilha e, consequentemente, o encontro e confronto de experiências de vida.

Sem qualquer ambição de definir o panorama atual de produção artística, apresento, resumidamente, três ideias: o webdocumentário enquanto ligação com o mundo da vida, uma evolução tecnológica com um impulso hiper-realista e um elemento central de todo o paradigma, o utilizador.

\section{O utilizador/explorador}

A teoria do cinema diz-nos que a relação espectador-filme nunca foi passiva. A tradição Psicanálise/cinema, nomeadamente as analogias entre espectador de cinema e sujeito da psicanálise (Aumont, 2002), assim como os atuais estudos sobre os efeitos emocionais e cognitivos dos filmes (cf., por exemplo, Carroll 1999) indicam claramente que o espectador, no momento da projeção do filme, está em constante relação com o mesmo, projetando-se, identificando-se ou fazendo inferências e suposições sobre, por exemplo, o desenvolvimento narrativo. Com a tecnologia digital interativa, as capacidades solicitadas ao espectador pelos meios associados à noção de representação, não são suficientes. A afetação emocional e capacidades cognitivas inerentes à relação espectador-filme não se desvanecem, mas acrescenta-se um apelo para executar ações, para exercer a interatividade. A relação das obras com o ainda "espectador" exige ação física, pois é necessário clicar em ícones, fazer escolhas, selecionar percursos. É precisamente esta exigência de ação física que torna o espectador em utilizador; ainda que as escolhas estejam sujeitas às possibilidades que lhe são fornecidas, o utilizador é convidado a seguir o seu próprio percurso e demorar o seu próprio tempo. Para além disso, estamos perante tecnologias com a possibilidade de comunicação em tempo real, o que, apesar de se tratar de uma comunicação tecnologicamente mediada, é experimentada como uma interação face-a-face.

Por definição, um produto ou serviço (e no caso, uma obra) é interativa se permite interação, sendo esta uma mútua ou recíproca ação ou influência (Svanaes 2013). A interatividade é uma característica inerente às novas tecnologias, assim não importa apenas dizer 
que as novas tecnologias são interativas, mas especificar os tipos de interatividade ou as consequências da mesma. E a consequência mais imediata é o utilizador poder construir o seu próprio percurso tornando-se assim, também, um coautor da obra (Manovich 2001a).

Para além disso, as tecnologias digitais seguem uma tendência já identificada e discutida pela teoria do cinema - tanto quanto se sabe, desde Hugo Münsterberg (1916) - a da tecnologia exteriorizar operações mentais.

O próprio princípio de hiperligar que é a base de grande parte dos meios interativos objetiva o processo de associação tido como central no pensamento humano. Processos mentais de reflexão, resolução de problemas, recordação e associação são exteriorizados, equiparados a seguir uma hiperligação, ir para uma nova página, escolher uma nova imagem ou uma nova cena. Antes [com os suportes lineares] olhávamos para uma imagem e seguíamos mentalmente as nossas associações privadas para outras imagens (...) Os media interativos convidam a que nos identifiquemos com a estrutura mental de alguém (...) o utilizador de um computador é convidado a seguir a trajetória mental de um designer de novos media. (Manovich 2001a, 74; trad. da A.)

O utilizador não é então um mero utilizador, já que as operações que realiza não são apenas operações físicas, há uma dimensão de afetação que é necessário considerar. As expectativas, interesses pessoais e mesmo emocionais interferem na fruição de uma obra. Assim, o utilizador não apenas acede a dados (imagem, texto, etc.) mas a sua interação está imbuída de aspetos de carácter psicológico, de motivações, de expectativas ou emoções e da sua familiaridade ou estranheza com uma determinada estrutura mental (interface).

Se o utilizador é convidado a entrar em interação com uma obra é porque se supõe que a mesma foi concebida para estimular essa interação. Esse estímulo depende da interface da obra e o maior ou menor sucesso de uma obra, assim como o seu valor interativo e mesmo criativo dependem, em muito, da facilidade ou dificuldade da interface, do quão simples ou complexas são as operações solicitadas. E todo o utilizador passará pelas fases de interação de: adaptação, aprendizagem, antecipação e conhecimento aprofundado (Bilda et al. 2008) sendo que apenas nesta última fase poderá existir efetiva interação (entendida enquanto influência mútua). No webdocumentário, assim como em qualquer outra obra, ou mesmo um simples site, uma mesma quantidade de dados pode ter diferentes interfaces. $\mathrm{O}$ desenvolvimento da interface terá como objetivo último que o utilizador possa imergir no "objeto" - para usarmos uma expressão de Manovich (2001a, 34) - ou, no caso que nos interessa, na obra, sem que a atenção do utilizador seja colocada na interface ela própria. Chamar a atenção para a interface em si seria um elemento de distração da utilização da obra - a não ser que se trate de uma obra que coloque, deliberadamente, o dispositivo como um fator de fruição ou cuja efetiva presença tenha de ser efetivamente notada. Mas, cada vez mais parece que a interação na qual se aposta é a que pretende substitui-se 
à interação face-a-face, uma vez que as tecnologias digitais possuem como característica principal a comunicação em tempo real.

No capítulo “O navegador e o explorador”, Manovich (2001a, 234) refere-se ao explorador como "o utilizador singular que navega através de um território desconhecido". A individualidade é, pelo menos por enquanto, um fator fundamental e essencial da fruição de uma obra interativa disponibilizada na Internet, como seja o webdocumentário.

Substituir utilizador por explorador assume no webdocumentário uma pertinência maior se tivermos em conta que Erik Barnouw (1983) no seu livro Documentary: A History of the Non-Fiction Film, apresenta uma evolução do documentário pelos papéis ou funções desempenhadas pelo realizador; e a primeira delas é a de explorador. Robert Flaherty com o seu filme Nanook, o Esquimó (1922) é, para Barnouw, o exemplo máximo do cineasta explorador. Por exemplo, a respeito da cena da construção do igloo, Barnouw refere que quando este aparenta estar concluído, Nanook começa a cortar um pedaço de gelo. O espectador não sabe para que servirá, só depois vê que o mesmo passa a ser uma janela. Nesse momento, Flaherty permite ao espectador ser, tal como ele, um explorador (Barnouw 1983, 40). Entendo que é precisamente neste ponto que reside o interesse do webdocumentário, a sua promessa de deixar que o utilizador assuma o papel de explorador, ou seja, aquele a quem é permitido seguir o seu próprio caminho de descoberta; de seguir uma pista que lhe despertou a atenção.

Se interveniente é o termo que, no documentário, substitui o termo de personagem usado para o filme de ficção, no webdocumentário faz todo o sentido que o termo de utilizador passe a explorador uma vez que o utilizador passa a ser mais um interveniente com um estatuto especial: é elemento central para a construção da interface e interação do webdocumentário.

O explorador poderá, mesmo que independentemente da sua maior ou menor capacidade de interação com o webdocumentário, ser um interveniente com maior ou menor envolvimento; e esse envolvimento não depende apenas das possibilidades que lhe são oferecidas mas, também, do seu próprio interesse nesse envolvimento. Assim, perante um mesmo webdocumentário, um dado explorador pode considerar que as possibilidades que lhe são oferecidas são suficientes e outro considerar que o webdocumentário não lhe permitiu relacionar-se efetivamente com a informação disponibilizada ou com os seus intervenientes.

Se a interatividade é algo que só por si nada diz a respeito do webdocumentário e se, nos estudos sobre os novos meios, os tipos de interatividade ocupam um lugar central, uma sistematização pelos tipos de utilizadores, ou aliás, exploradores, não seria de todo um exercício inútil. Aqui uma questão que surge é precisamente a do pa- 
pel desse explorador cuja interação é mediada pelo computador. Por certo, papéis diversos, dependendo dos seus interesses e expectativas, do próprio webdocumentário e seus objetivos, interface, tema, etc. Mas, uma outra questão que apresento a seguir e que considero mais urgente é a de propor uma compreensão a respeito do modo como o webdocumentário aborda o mundo da vida.

\section{Abordagens e navegação}

Sendo a interatividade uma condição inerente a toda e qualquer obra em suporte digital, dizer que um webdocumentário é interativo só por si nada diz a respeito de todo e qualquer webdocumentário. A experiência em si de interagir com uma obra passa por uma relação mais direta com essa mesma obra. A interatividade é um princípio englobante a partir do qual o confronto direto com um webdocumentário irá permitir diferentes tipos de navegação. Ou seja, não é por causa do tipo de interatividade possibilitada, mas pelo tipo de navegação experimentada que o explorador estabelece um relacionamento concreto com o webdocumentário e com o mundo da vida.

No webdocumentário, identifico dois tipos de abordagem e navegação: uma abordagem centrada e uma abordagem global, a que correspondem uma navegação disseminada e cumulativa, respetivamente.

$\mathrm{Na}$ abordagem centrada, o webdocumentário delimita espacial e/ou temporalmente o seu tema, oferecendo um tipo ou dinâmica de navegação disseminada, ou seja, a navegação pelo webdocumentário implica que o explorador faça um determinado conjunto de escolhas por entre os conteúdos disponibilizados. São obras, em geral, com uma estrutura em menus e submenus, cujo interface é de maior ou menor criatividade, mas a estrutura é relativamente rígida uma vez que está em causa um percurso. Um exemplo deste tipo de abordagem e navegação é Journey to the End of Coal (2008), de Samuel Bollendorf e Abel Ségrétin, sobre as condições de vida nas minas de carvão de Datong, província de Shanxi, China. Logo no início do webdocumentário, legendas brancas sobre um fundo preto referem o crescimento económico e é dito que a China se tornou recentemente a terceira maior potência económica. A finalizar este texto inicial, ao explorador é proposto o seguinte papel: "enquanto jornalista freelancer, decidiu investigar as condições de vida daqueles que tornam o 'milagre chinês' possível. Irá começar a sua investigação focando as minas de carvão mais perigosas do mundo... A viagem que está prestes a fazer baseia-se inteiramente em factos reais; apenas os nomes foram alterados." A partir do menu inicial clicar em "Take a train to Shanxi" remete para um pequeno filme no interior de um comboio com os créditos iniciais e após alguma informação de carácter mais factual em legenda, surge um outro menu com as opções "Visit the state mine complex" e "Go look for coal miners". A partir da primeira 
opção, é-nos dito, em legenda, que se trata de uma visita oferecida pelas autoridades locais e que teremos um guia a acompanhar-nos. Chegados a uma fotografia de um mineiro estão duas perguntas: "Hello. Do accidents often occur in this mine?" e "Hello. Aren't you afraid to go down, given the high rates of accidents?" A partir de qualquer uma destas perguntas, apenas ouvimos dizer que não, nunca houve nenhum acidente e que não estamos autorizados a falar com mineiros, pelo que surgem duas opções: "Ask a less embarrassing question" e "Follow your guide and go back up meet the director". De um modo geral, este webdocumentário assenta na transmissão de informação factual em legenda e oferece exatamente aquilo que Barnouw entendeu ser a cena da construção do igloo, um espectadorexplorador. No caso, mesmo quando não é permitido o acesso a determinada informação, facilmente se compreende o porquê e o explorador é estimulado a procurar um conhecimento mais aprofundado e esclarecido a respeito da situação vivida pelos mineiros. Este é um webdocumentário claramente de denúncia que expõe e sensibiliza o explorador para o que está por detrás do "brilhantismo" de uma potência económica.

$\mathrm{Na}$ abordagem global, o tema tratado abre a hipótese de serem acrescentadas novas situações, experiências de vida, testemunhos ou acontecimentos já que esses mesmos temas não apresentam uma delimitação espacial nem temporalidade específica (acontecem aqui, ali, a mim, ao Outro, hoje, amanhã...). Aqui ocorre um tipo de navegação cumulativa já que é possível, e de modo infinito, acrescentar novas situações, experiências, testemunhos, etc. É o caso de Qui va Garder les Enfants? (2011), de Francine Raymond, um webdocumentário sobre o dia-a-dia de diferentes famílias com filhos, construído por uma infografia com linhas verticais em que cada cor corresponde a uma família: "casados, 4 filhos", "o pai com guarda alternada", "duas mães", "os pais em horários deslocados", "a mãe sozinha” e "os pais, nova geração". Esta é uma obra de fácil navegação e a participação do explorador passa pelo seu testemunho, o que contribui para um maior envolvimento emocional. Um outro webdocumentário exemplificativo da abordagem global é o assaz conhecido Out my window - High Rise (2009/2013), de Katerina Cizek.

Esta abordagem global aparenta estar sempre inacabada. A incompletude é o que aparenta caracterizar, de um modo geral, as obras intituladas de webdocumentário e, por extensão, também o que sobre elas é dito. Assim sendo, e apenas enquanto conclusão (eventualmente provisória), o que neste texto acabámos de apresentar é que o webdocumentário resulta de uma ligação entre a Internet e o documentário e que se trata de uma obra que, no âmbito do atual panorama de produção artística, contribui não apenas para uma evolução do documentário, pois torna-o interativo mas, também, para uma evolução das tecnologias digitais interativas, pois estas passam a apresentar-se como mais que um mero suporte de dados. Defendi o 
webdocumentário como um recorte do mundo da vida com dois tipos de abordagem: centrada e global, a que correspondem uma navegação disseminada e cumulativa, respetivamente, nas quais o utilizador assume o papel de explorador.

\section{BIBLIOGRAFIA}

Aumont, Jacques. 2002. A Estética do Filme. 2a Edição. Papirus Editora.

Barnouw, Erik. 1983. Documentary, A History of the Non-Fiction Film. Oxford/New York/Toronto/Melbourne: Oxford University Press. [1974].

Bazin, André. 1946. "O mito do cinema total.” In O que é o cinema? Lisboa: Livros Horizonte. [1992].

Bilda, Zafer, Ernest Edmonds e Linda Candy. 2008. "Designing for creative engagement." Design Studies 29 (6): 525-540.

Carroll, John M. 2013. "Human Computer Interaction - brief intro." In The Encyclopedia of Human-Computer Interaction, $2^{\mathrm{a}}$ ed., ed. Mads Soegaard, Rikke Friis Dam. Aarhus, Denmark: The Interaction Design Foundation.

http://www.interactiondesign.org/encyclopedia/human_com puter_interaction_hci.html

Carroll, Noël. 1999. "Film, emotion and genre." In Passionate Views Film, Cognition and Emotion, ed. Carl Plantinga, Greg M. Smith. Johns Hopkins University Press.

Gantier, Samuel. 2011. "L'expérience immersive du web documentaire: études de cas et pistes de réflexion." Les Cahiers du Jornalisme no 22/23 - Automne: 118-133.

Manovich, Lev. 2001a. The Language of New Media. Cambridge: MIT Press. Acedido em novembro de 2013. http://www.academia.edu/542739/The_language_of_new_m edia

———. 2001b. “A program for post-media aesthetics." In Post-Media Aesthetics. Acedido em novembro de 2013. http://www.manovich.net/DOCS/Post_media_aesthetics1.do c

Morin, Edgar. 1997. O Cinema ou o Homem Imaginário. Lisboa: Relógio D’Água [Orig. 1956].

Münsterberg, Hugo. 1916. The Photoplay: A Psychological Study. Acedido em novembro de 2013. http://www.gutenberg.org/ebooks/15383 
Svanaes, Dag. 2013. "Philosophy of Interaction." In The Encyclopedia of Human-Computer Interaction, ed. Mads Soegaard, Rikke Friis Dam. $2^{\mathrm{a}}$ ed. Aarhus, Denmark: The Interaction Design Foundation.

http://www.interactiondesign.org/encyclopedia/human_com puter_interaction_hci.html

\section{WEBDOCUMENTÁRIOS}

Journey to the End of Coal [webdocumentário, online] Real. Samuel Bollendorf e Abel Ségrétin. Honkytonk Films, Klynt Editing \& publishing app, França, 2008.

http://www.honkytonk.fr/index.php/webdoc/ (acedido em novembro de 2013)

Qui va Garder les Enfants? [webdocumentário, online] Real. Francine Raymond. Découpages; France Télévisions; com a participação do CNC-Centre National du Cinéma et de l'Image Animée, França, 2011. http://www.francetv.fr/nouvellesecritures/qui-va-garder-les-enfants/ (acedido em novembro de 2013).

Out my window - High Rise [webdocumentário, online] Real.

Katerina Cizek. NFB-National Film Board of Canada, Canadá, 2009/2013. http://highrise.nfb.ca/tag/out-my-window/ (acedido em novembro de 2013). 